\title{
Smart Control of Buck Converters using a Switching-based Clustering Algorithm
}

\author{
Brook Abegaz \\ babegaz@luc.edu \\ M. Cmiel
}

Follow this and additional works at: https://ecommons.luc.edu/engineering_facpubs

Part of the Computer Engineering Commons

\section{Recommended Citation}

Abegaz, Brook and Cmiel, M., "Smart Control of Buck Converters using a Switching-based Clustering Algorithm" (2019). Engineering Science Faculty Publications. 4.

https://ecommons.luc.edu/engineering_facpubs/4

This Conference Proceeding is brought to you for free and open access by the Faculty Publications and Other Works by Department at Loyola eCommons. It has been accepted for inclusion in Engineering Science Faculty Publications by an authorized administrator of Loyola eCommons. For more information, please contact ecommons@luc.edu.

\section{(c) $($ ()}

This work is licensed under a Creative Commons Attribution-Noncommercial-No Derivative Works 3.0 License. (C) 2019 IEEE. 


\title{
Smart Control of Buck Converters using a Switching- based Clustering Algorithm
}

\author{
B. Abegaz, Member, IEEE, M. Cmiel, Student Member, IEEE
}

\begin{abstract}
This paper proposes a new approach to the control of switching voltage regulators (buck converters). The method is performed using a switching-based clustering algorithm. The implementations of competing approaches such as a fuzzy-logic controller, proportional integral derivative controller and a neural network based controller are presented in order to compare and evaluate the performance of the switching-based clustering algorithm. The results of the approach show that the proposed method could improve the stability and the performance of the buck converter system by $2.7 \%$ in terms of settling time and by $0.6 \%$ in terms of the overshoot value as compared to other control methods for buck converters.
\end{abstract}

Keywords-control systems; power converters; unsupervised machine learning; switching; clustering

\section{INTRODUCTION}

As a type of switching voltage regulator, a buck converter, also known as a direct current (DC) step down converter, takes an input voltage, and outputs a lower voltage. Buck converters are extremely versatile in various applications where they are used to easily control an input voltage or input current regardless of a variety of factors such as frequency and temperature [1], [2]. Applications of the buck converter include the power supplies of laptops and mobile phones as well as the power type and level conversion from solar panels. As an example, in Figure 1a, a motherboard of a computer is shown that uses an on-board buck converter. A laptop which uses a buck converter in order to charge its battery is shown in Figure 1b. A foldable solar panel charger used by hikers which takes a non-linear input voltage and converts it into a useable voltage is shown in Figure 1c.
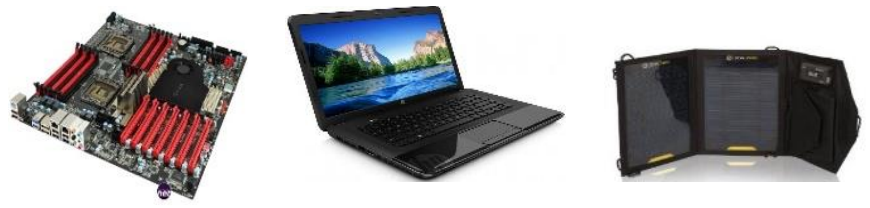

Figure 1a,1b,1c: Application areas of buck converters [3]

A more advanced buck controller system would allow for a more efficient and cost-effective use of the previous applications for the buck controller as well as an easier way to control the outputs of systems of all classifications. Recent literature regarding the control of buck converter systems has focused on the use of either proportional integral derivative (PID) controllers or fuzzy logic controllers that control the input to a pulse width modulator (PWM) generator in order to control the gain of a metal-oxide-semiconductor field effect transistor (MOSFET) [2], [4], [5]. This paper presents a comparison of the different controllers for a buck converter system and proposes a new, unsupervised machine learning controller which uses a switching-based clustering algorithm for the improvement of the stability of the buck converter output.

\section{BUCK CONVERTER CONTROL}

A conventional buck converter system consists of two switches, a MOSFET, a diode, and resistor-inductor-capacitor (RLC) elements that filter and lower voltage levels. The load resistor functions as an output load [2], [6]. In order to more effectively implement the conventional buck converter, the system equations and system differential equations were calculated.

\section{A. State Space Equations}

The state space equations of the buck converter system are given in (1), (2), and (3). The state variables were chosen to be the voltage through the capacitor $V_{c}(t)$ and the current across the inductor $i_{L}(t)$. The system differential equations that were found using Kirchhoff's voltage and current laws are given in (4) and (5), where $u(t)$ is an input function. The output equation in terms of the state variables is given in (6). The transfer function, $\mathrm{G}(\mathrm{s})$ is generated from the system differential equations as given in (7), where the complex frequency $s=$ sigma $+j^{*}$ omega.

$$
\begin{gathered}
x(t)=\left[x_{1}(t), x_{2}(t)\right] \\
x_{1}(t)=V_{c}(t) \\
x_{2}(t)=i_{L}(t) \\
\dot{x}_{1}(t)=-\frac{1}{R C} x_{1}(t)+\frac{1}{C} x_{2}(t) \\
\dot{x}_{2}(t)=-\frac{1}{L} x_{1}+\frac{1}{L} u(t) \\
y=V_{R}(t)=V_{C}(t) \\
G(s)=\frac{1}{s^{2} C L+\frac{s L}{R}-1}
\end{gathered}
$$

\section{B. Conventional Controllers}

The PID controller is one example of conventional control approaches, which has been widely implemented and addressed in literature. The PID controller is implemented in series with a PWM generator leading to the gain of the MOSFET transistor [7], [8], [9]. The input to the PID controller was generated from the feedback loop of the converter.

As shown in Figure 2, the output of the controller was fed back and the error was calculated from a reference voltage of $3 \mathrm{~V}$. The output is given to the PID controller. The proportional gain of the controller was set to a value of 1 . The integral gain of the controller was set to a value of 1 . The derivative gain of 
the controller was set to a value of 0 . The filter coefficient of the controller was set to a value of 100. Finally, the time domain of the controller was set to continuous time.

\section{Fuzzy Logic Controller}

The fuzzy logic controller is another competing approach to buck converter control seen in contemporary literature. The fuzzy logic controller was implemented so that its output is the gain of the MOSFET transistor. The fuzzy logic controller is a method of control that utilizes various membership functions in order to generate a set of values between 0 and 1 that correspond to the inputs given [1], [2].

As shown in Figure 2, the output of the controller is given to the PWM generator. The rules of the fuzzy logic controller were designed comparably to the inputs and outputs of the PID controller. In the controller, the number of samples for output discretization was set to a value of 101 .

\section{Neural Network Predictive Controller}

The neural network predictive controller is another competing approach to buck converter control. In implementing the neural network predictive controller, the feedback voltage was given as the reference for the neural network system, the load voltage was given as the plant output for the neural network, and the control signal from the neural network model was set as the input to the PWM generator of the buck converter.

In the implementation, the input and output arrays of the controller were taken from the input and output of the PWM from the original buck converter model and the number of training epochs was set to 100. After training the input and output, the testing data, validation data, and training data for the controller were recorded.

\section{Proposed Control Approach - Switching BASED Clustering AlgORITHM}

Clustering is an unsupervised machine learning technique in which data is grouped into clusters based on their similarity. The clusters are mutually exclusive [10]. The most common types of clustering algorithms used include K-means clustering and hierarchical clustering. Being able to form clusters based on observations rather than numerical comparisons makes clustering a useful unsupervised machine learning approach for larger amounts of data [10], [11].

Although adaptive controllers have been used in conventional buck converter systems in the past [11], [12], the use of switching-based clustering algorithm is a novel method of control.

A model of the proposed switching-based clustering controller with the buck converter is shown in Figure 2. The switching-based clustering algorithm groups the output voltage of the converter into three clusters based on similarity and then based on the clustering coefficients and indices, the switching frequencies of the PWM were adjusted. The switching-based clustering algorithm is shown in Algorithm 1, where the output needed to be converted to a time-series and then, it could be grouped into switching clusters.

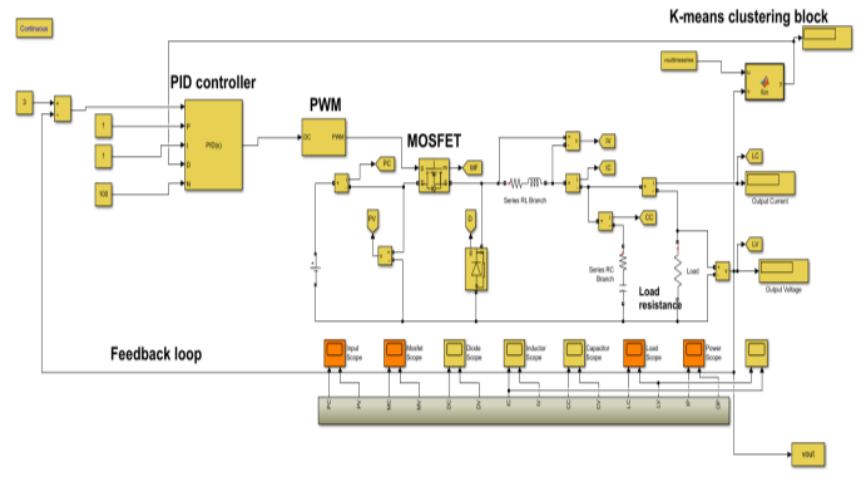

Figure 2: A model of the switching-based clustering controller

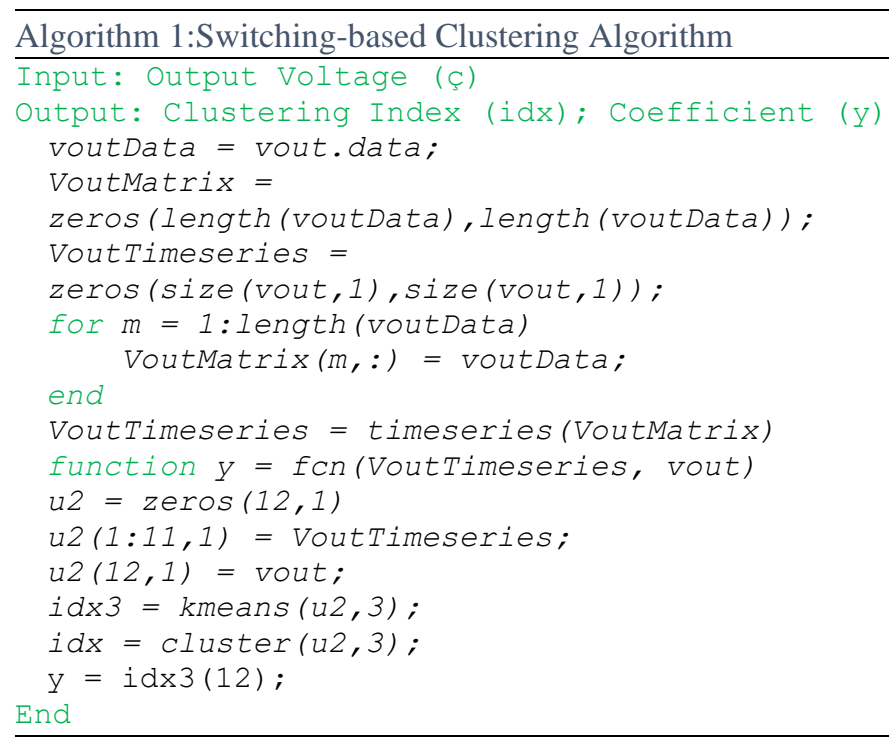

After obtaining pertinent data with the original signal, a new reference voltage signal shown in Figure 3 was implemented that was set to pulse three times between the values of $3 \mathrm{~V}$ and $5 \mathrm{~V}$. This new reference was implemented in place of the constant $3 \mathrm{~V}$ into the gain of the MOSFET. The purpose was to determine if the system is able to learn from the previous pulsed input and decrease the fall time to the desired output voltage.

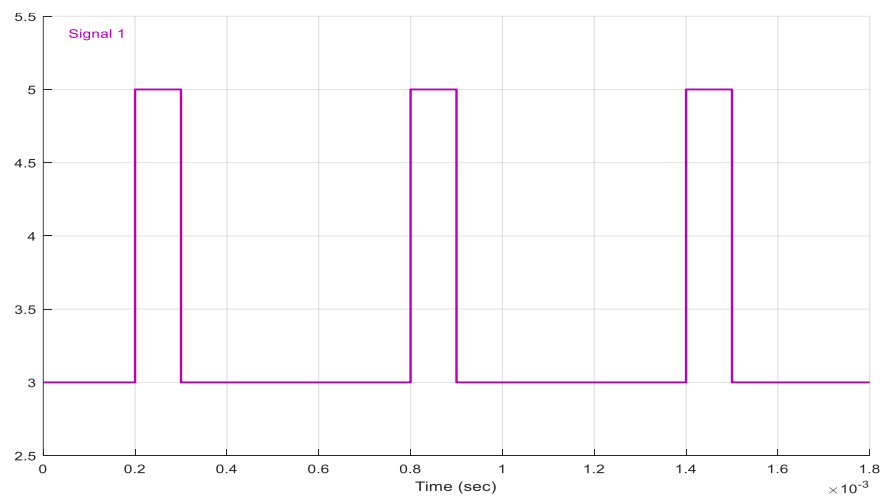

Figure 3: A pulsed reference voltage signal 


\section{RESULTS}

After implementing the PID controller, the fuzzy logic controller and the k-means clustering algorithm into the buck converter system, the following results were observed.

\section{A. Implementation of the PID controller in a buck converter}

After implementating the PID controller into the buck converter described in Section II, the load current and voltage are shown in Figure 4. The load current and voltage are obtained by implementing the PID controller with a single input to the gain of the MOSFET. The data from the load current and voltage is used when comparing the PID controller to the other controllers implemented.
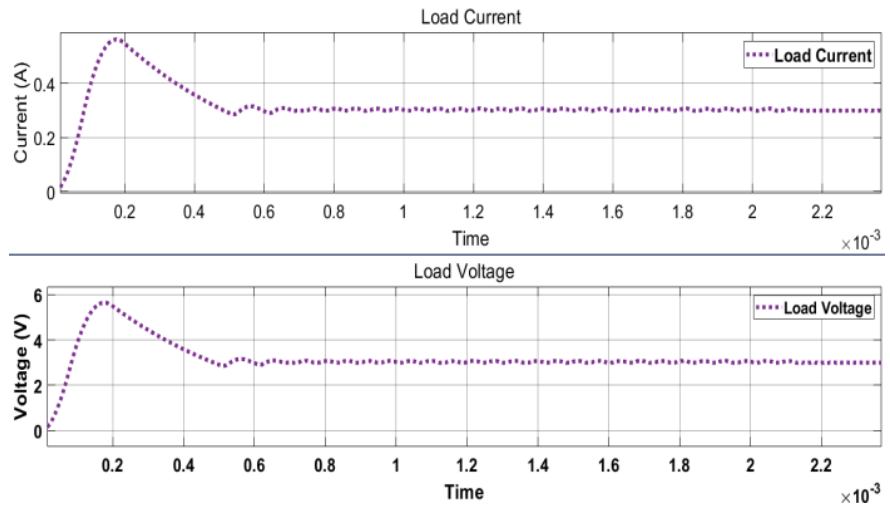

Figure 4: Load current and load voltage

\section{B. Implementation of Fuzzy Controller in the Buck Converter}

The results of the implementation of the fuzzy logic controller are shown in Figure 5. The load voltage and current values are obtained from implementing the fuzzy logic controller with a single input to the gain of the MOSFET.
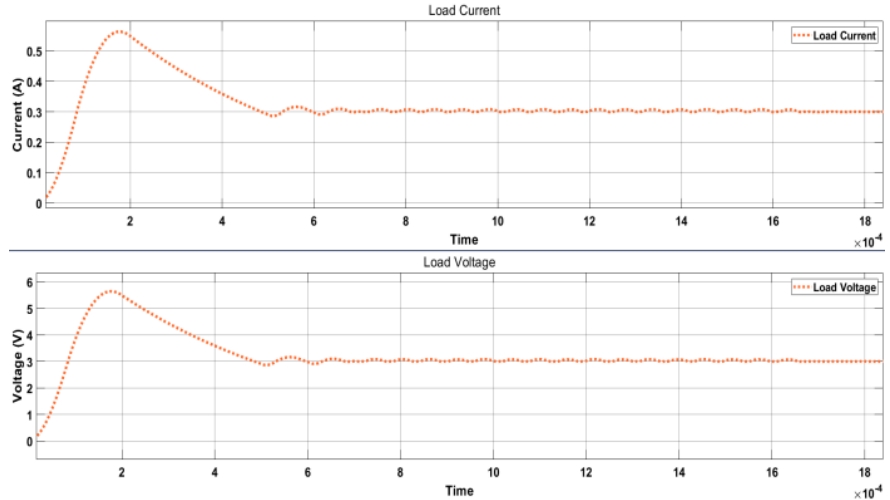

Figure 5: Load current and load voltage

\section{Implementation of Switching-based Clustering Controller}

The results of the implementation of the switching-based clustering algorithm are shown in Figure 6, Figure 7, and Figure 8 . The load current and voltage are shown in Figure 6 . The data from the load was used when comparing the proposed controller to the other controllers as given in Table 1 and Table 2.
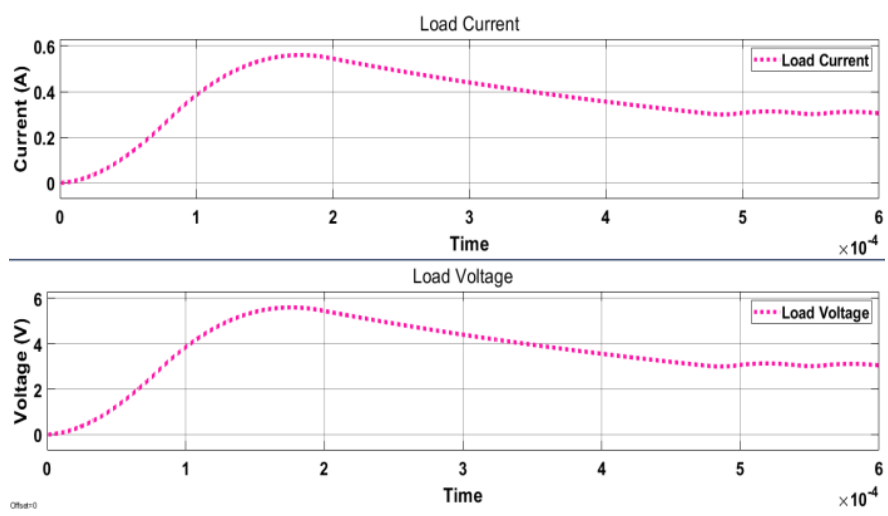

Figure 6: Load current and load voltage

The MOSFET gate current and voltage is shown in Figure 7 and the input and the output power are shown in Figure 8. The input and the output power values are obtained from implementing the unsupervised machine learning controller with a single input to the MOSFET gate terminal.
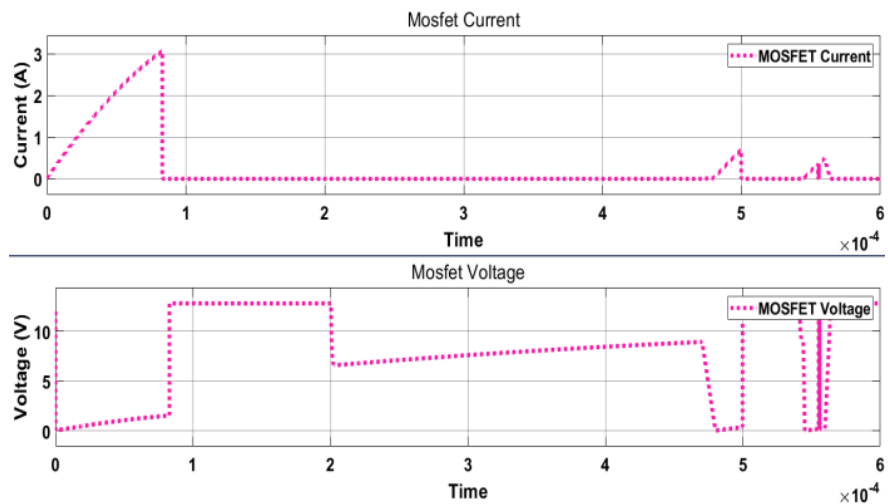

Figure 7: MOSFET gate current and voltage
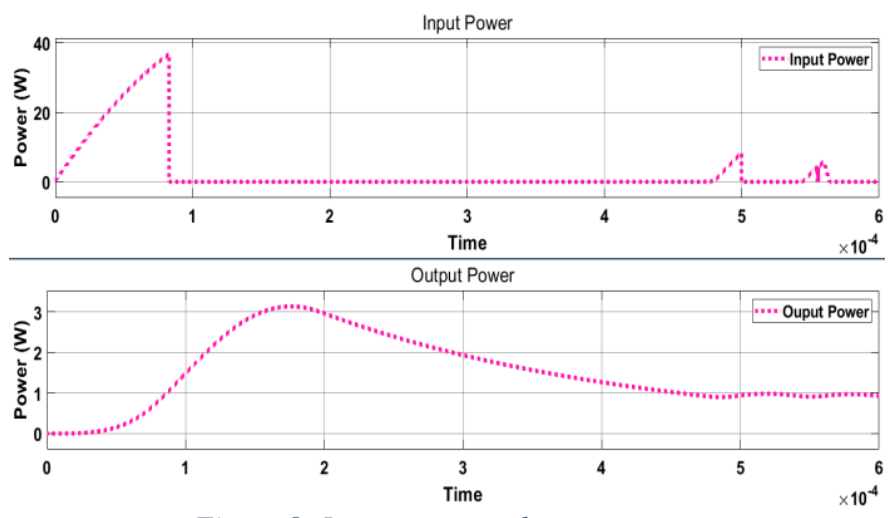

Figure 8: Input power and output power

A comparison of the load voltages and load currents of the original converter (in yellow), the PID controlled converter (in pink), the fuzzy logic controlled converter (in purple), and the switching-based clustering controlled converter (in blue) are shown in Figure 9. 

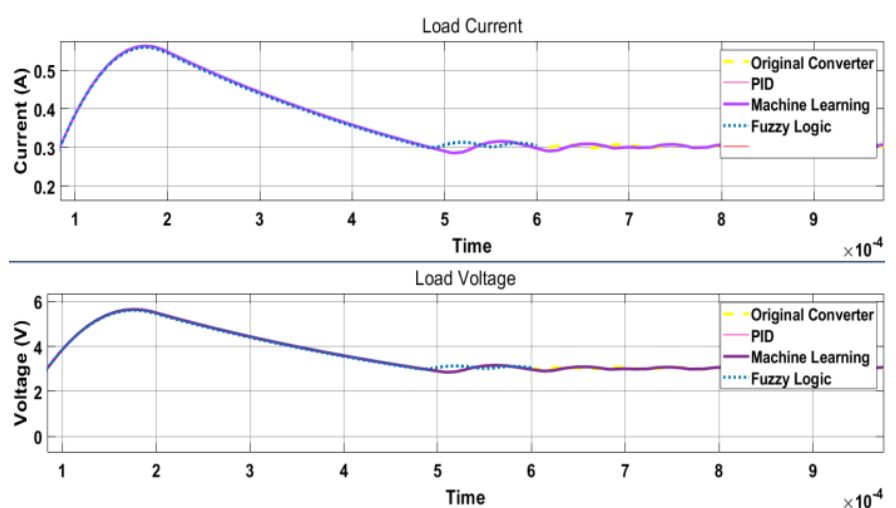

Figure 9: A Comparison of the load currents and load voltages

The rise time, fall time, overshoot, initial value, peak value, settling time and final value of the outputs of the controllers that were implemented are compared in

Table 1. The rise time was calculated as the time required for the voltage to rise from its initial value to $90 \%$ of its peak value. The fall time was calculated as the time it takes for the voltage to go from peak value $V_{\text {peak }}$ to $98 \%$ of its stabilized value $V_{\text {stable }}$. Settling time was calculated as the time needed for the voltage to go from the initial value to within $98 \%$ of its final or stabilized value. The overshoot (OS) was calculated as given in (8).

$$
O S=V_{\text {peak }}-V_{\text {stable }}
$$

Table 1: Stability Comparison of Output Voltage at Fixed Reference

\begin{tabular}{|c|c|c|c|c|}
\hline & $\begin{array}{c}\text { Feedback } \\
\text { Control }\end{array}$ & $\begin{array}{c}\text { PID } \\
\text { Control }\end{array}$ & $\begin{array}{c}\text { Fuzzy } \\
\text { Logic } \\
\text { Control }\end{array}$ & $\begin{array}{c}\text { Switching- } \\
\text { based } \\
\text { Clustering }\end{array}$ \\
\hline Rise Time & $1.752 \mathrm{e}-4 \mathrm{~s}$ & $1.754 \mathrm{e}-4 \mathrm{~s}$ & $1.776 \mathrm{e}-4 \mathrm{~s}$ & $1.751 \mathrm{e}-4 \mathrm{~s}$ \\
\hline Fall Time & $3.264 \mathrm{e}-4 \mathrm{~s}$ & $3.39 \mathrm{e}-4 \mathrm{~s}$ & $3.26 \mathrm{e}-4 \mathrm{~s}$ & $\mathbf{3 . 1 3 e}-4 \mathrm{~s}$ \\
\hline Overshoot & $2.604 \mathrm{~V}$ & $2.634 \mathrm{~V}$ & $2.641 \mathrm{~V}$ & $\mathbf{2 . 5 8 8 V}$ \\
\hline Initial value & $0 \mathrm{~V}$ & $0 \mathrm{~V}$ & $0 \mathrm{~V}$ & $0 \mathrm{~V}$ \\
\hline Peak value & $5.639 \mathrm{~V}$ & $5.64 \mathrm{~V}$ & $5.635 \mathrm{~V}$ & $5.639 \mathrm{~V}$ \\
\hline Final value & $2.863 \mathrm{~V}$ & $2.868 \mathrm{~V}$ & $2.863 \mathrm{~V}$ & $\mathbf{3 . 0 1 0 V}$ \\
\hline Settling time & $\mathbf{5 . 0 1 6 e - 4 s}$ & $5.144 \mathrm{e}-4 \mathrm{~s}$ & $5.036 \mathrm{e}-4 \mathrm{~s}$ & $\mathbf{4 . 8 8 1 e}-4 \mathrm{~s}$ \\
\hline
\end{tabular}

The rise time, fall time, overshoot, initial value, peak value, and final value of the input to the PWM of the controllers that were implemented is compared in Table 2.

Table 2: Stability Comparison of PWM Input Voltage

\begin{tabular}{|c|c|c|c|c|}
\hline & $\begin{array}{c}\text { Feedback } \\
\text { Control }\end{array}$ & $\begin{array}{c}\text { PID } \\
\text { Control }\end{array}$ & $\begin{array}{c}\text { Fuzzy } \\
\text { Logic }\end{array}$ & $\begin{array}{c}\text { Switching- } \\
\text { based } \\
\text { Clustering }\end{array}$ \\
\hline Rise Time & $0 \mathrm{~s}$ & $0 \mathrm{~s}$ & $0 \mathrm{~s}$ & $3.84 \mathrm{e}-4 \mathrm{~s}$ \\
\hline Fall Time & $2.24 \mathrm{e}-3 \mathrm{~s}$ & $2.18 \mathrm{e}-3 \mathrm{~s}$ & $1.64 \mathrm{e}-3 \mathrm{~s}$ & $5.999 \mathrm{e}-4 \mathrm{~s}$ \\
\hline Overshoot & $3.010 \mathrm{~V}$ & $2.998 \mathrm{~V}$ & $2.874 \mathrm{~V}$ & $6.33 \mathrm{e} 3 \mathrm{~V}$ \\
\hline Initial Value & $2.99 \mathrm{~V}$ & $2.999 \mathrm{~V}$ & $2.876 \mathrm{~V}$ & $6.024 \mathrm{e} 2 \mathrm{~V}$ \\
\hline Peak Value & $2.99 \mathrm{~V}$ & $2.999 \mathrm{~V}$ & $2.876 \mathrm{~V}$ & $1.291 \mathrm{e} 4 \mathrm{~V}$ \\
\hline Final Value & $-1.09 \mathrm{e}-2 \mathrm{~V}$ & $5.09 \mathrm{e}-4 \mathrm{~V}$ & $2.15 \mathrm{e}-3 \mathrm{~V}$ & $6.582 \mathrm{e} 3 \mathrm{~V}$ \\
\hline
\end{tabular}

\section{Implementation of PID Controller with a Pulsed Reference}

The results of the PID controller implementation with the pulsed reference are shown in Figure 10. The acquired load current and voltage both were as expected due to the introduction of the three pulsed input to the gain of the MOSFET.
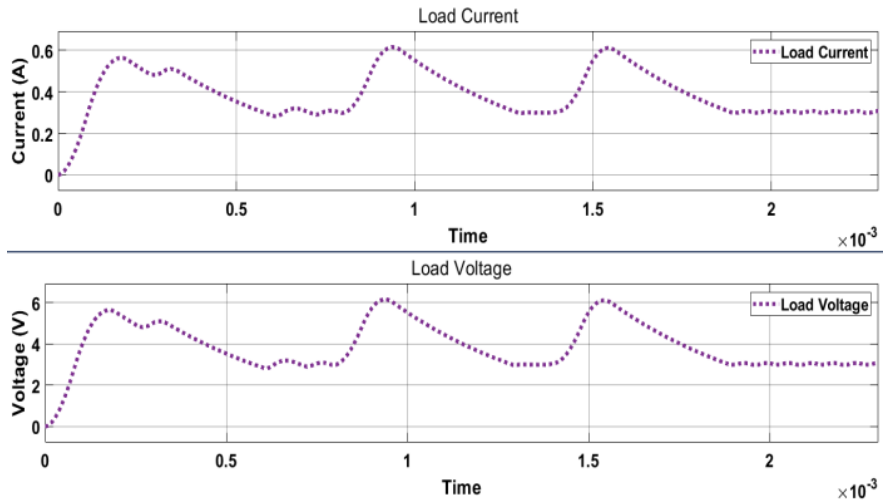

Figure 10: Load current and load voltage with pulsed reference

The MOSFET current and voltage with the pulsed reference are shown in Figure 11 and the input and output power with the pulsed reference is shown in Figure 12. The input and output power were also both as expected due to the introduction of the new three pulsed input to the gain of the MOSFET.
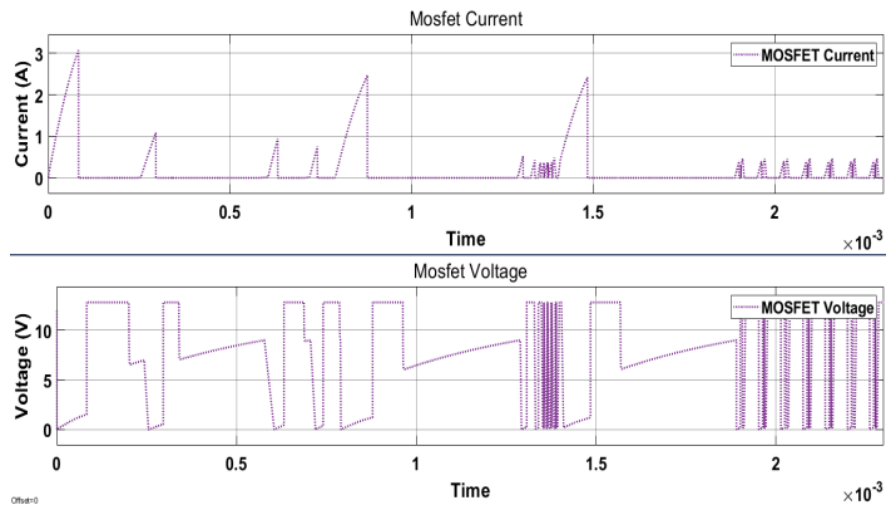

Figure 11: MOSFET current and voltage with pulsed reference
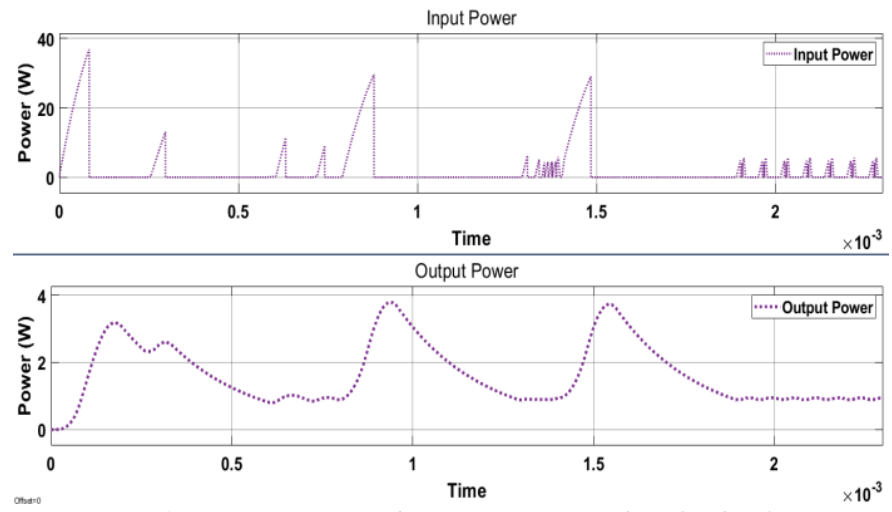

Figure 12: Input power and output power with pulsed reference 


\section{E. Implementation of Switching-based Clustering Controller} with a Pulsed Reference Voltage

The results of the implementation of the unsupervised machine learning controller which uses the switching-based clustering algorithm with the new pulsed reference are shown in Figure 13, Figure 14 and Figure 15. The data obtained from the load current and load voltage were used when comparing the unsupervised machine learning controller to the other controllers implemented using the pulsed reference. The load current and voltage with the new input are shown in Figure 13.
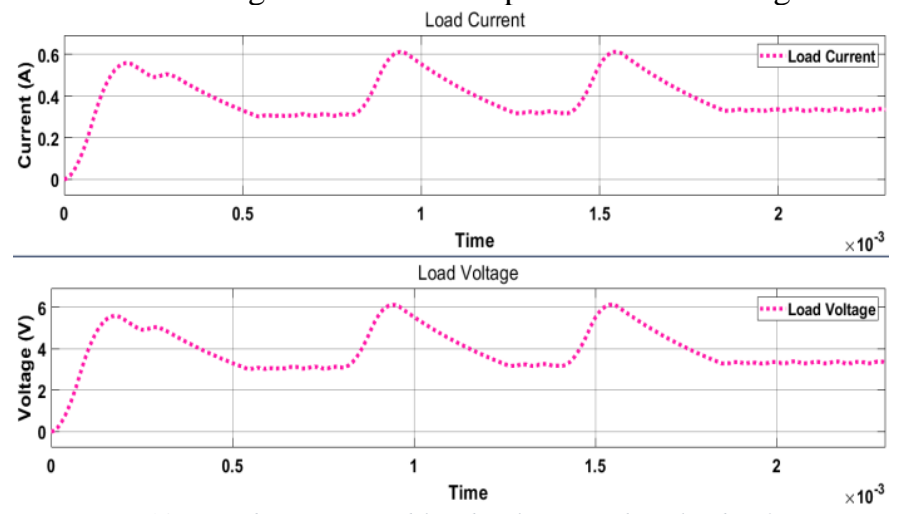

Figure 13: Load current and load voltage with pulsed reference

The MOSFET current and voltage with the new reference are shown in Figure 14 and the input and output power with the new input are shown in Figure 15. The input and output power were also both as expected due to the introduction of the new three pulsed input to the switching of the MOSFET.
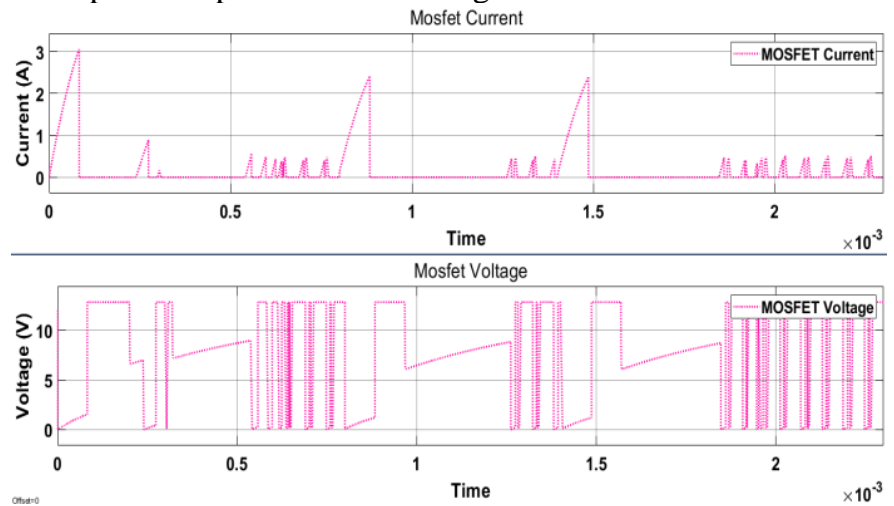

Figure 14: MOSFET current and voltage with pulsed reference
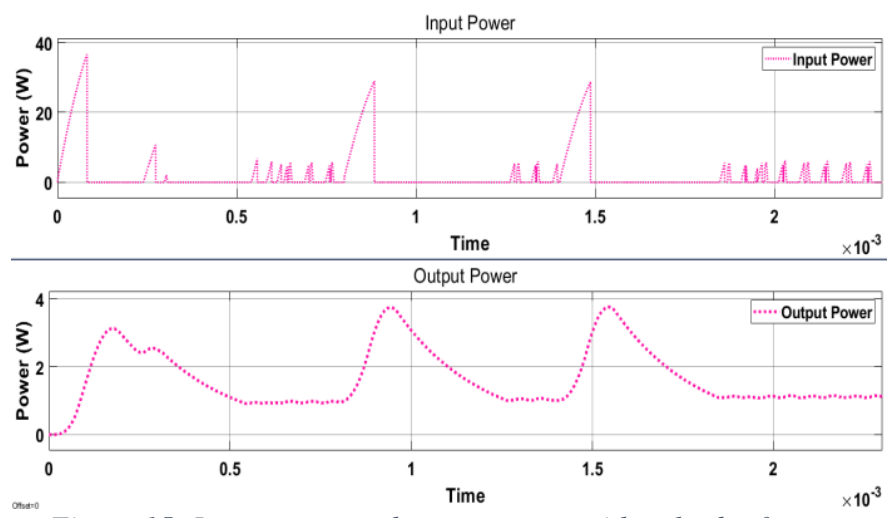

Figure 15: Input power and output power with pulsed reference

\section{F. Implementation of fuzzy logic controller with pulsed input}

The results of the implementation of the fuzzy logic controller with the new pulsed reference are shown in Figure 16. The data obtained from the figure of the load current and load voltage was used when comparing the fuzzy logic controller to the other implemented controllers.

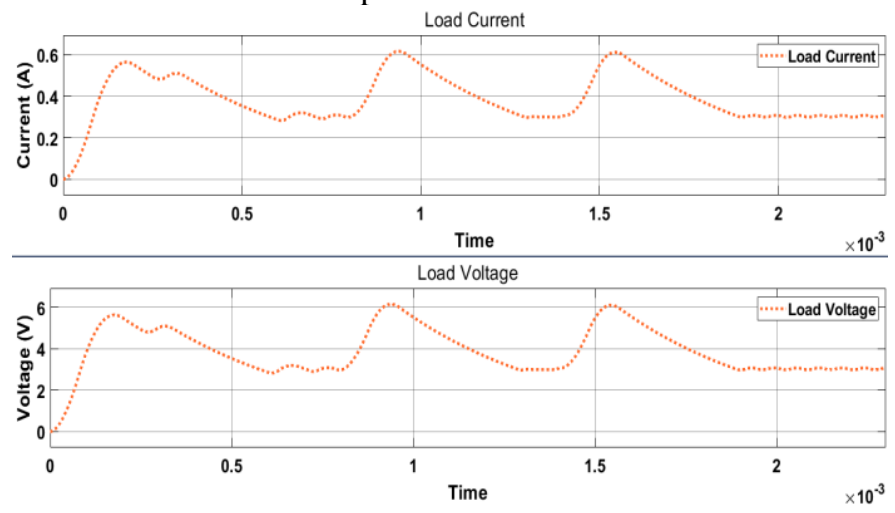

Figure 16: Load current and load voltage with pulsed reference

A comparison of the load voltages and the load currents of the converter with the PID implemented (in pink), with the fuzzy logic controller implemented (in purple) and with the switching-based clustering implemented (in blue) for the system with the pulsed reference is shown in Figure 17.
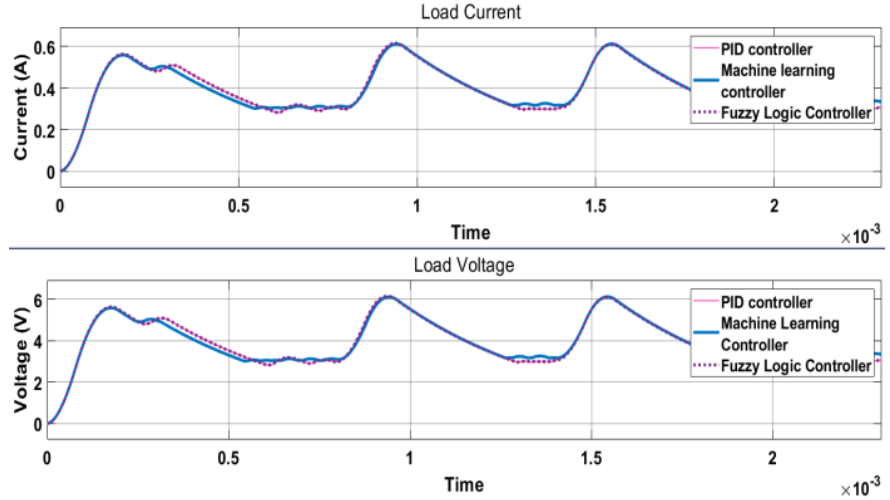

Figure 17: Comparison of load currents and load voltages with pulsed reference

The rise time, fall time, overshoot, initial value, peak value, and final value of the controller outputs for the first two peaks recorded with the pulsed reference are compared in Table 3.

Table 3: Stability Comparison of Output Voltage at Pulsed Reference
\begin{tabular}{|c|c|c|c|}
\hline & PID & Fuzzy Logic & $\begin{array}{c}\text { Switching-based } \\
\text { Clustering }\end{array}$ \\
\hline Rise Time-Peak 1 & $1.73 \mathrm{e}-4 \mathrm{~s}$ & $1.738 \mathrm{e}-4 \mathrm{~s}$ & $1.735 \mathrm{e}-4 \mathrm{~s}$ \\
\hline Fall Time -Peak 1 & $7.96 \mathrm{e}-4 \mathrm{~s}$ & $7.936 \mathrm{e}-4 \mathrm{~s}$ & $8.030 \mathrm{e}-4 \mathrm{~s}$ \\
\hline Overshoot- Peak 1 & $2.649 \mathrm{~V}$ & $2.651 \mathrm{~V}$ & $2.491 \mathrm{~V}$ \\
\hline Initial Value & $1.2 \mathrm{e}-3 \mathrm{~V}$ & $1.2 \mathrm{e}-3 \mathrm{~V}$ & $1.2 \mathrm{e}-3 \mathrm{~V}$ \\
\hline Peak Value - Peak 1 & $5.634 \mathrm{~V}$ & $5.634 \mathrm{~V}$ & $5.585 \mathrm{~V}$ \\
\hline Final Value-Peak 1 & $2.894 \mathrm{~V}$ & $2.983 \mathrm{~V}$ & $3.094 \mathrm{~V}$ \\
\hline Rise Time-Peak 2 & $9.39 \mathrm{e}-4 \mathrm{~s}$ & $\mathbf{9 . 3 6 e}-4 \mathrm{~s}$ & $9.39 \mathrm{e}-4 \mathrm{~s}$ \\
\hline Fall Time-Peak 2 & $\mathbf{1 . 3 8 e - 3 s}$ & $1.3874 \mathrm{e}-3 \mathrm{~s}$ & $1.404 \mathrm{e}-3 \mathrm{~s}$ \\
\hline Overshoot- Peak 2 & $3.155 \mathrm{~V}$ & $3.156 \mathrm{~V}$ & $\mathbf{2 . 9 4 0 V}$ \\
\hline Peak Value - Peak 2 & $6.154 \mathrm{~V}$ & $\mathbf{6 . 1 5 6 V}$ & $6.115 \mathrm{~V}$ \\
\hline Final Value-Peak 2 & $2.999 \mathrm{~V}$ & $\mathbf{3 . 0 0 V}$ & $3.175 \mathrm{~V}$ \\
\hline
\end{tabular}




\section{DISCUSSION}

A comparison of the initial experiment with a constant reference voltage showed that the unsupervised machine learning controller with the switching-based clustering algorithm performed better than the other control approaches as shown in Table 4. The switching-based clustering controller had the quickest rise time and fall time of $1.75 \times 10^{-4} \mathrm{~s}$ and $3.13 \times 10^{-4} \mathrm{~s}$ respectively and had the lowest overshoot and a final value that was closest to the desired output voltage of $3 \mathrm{~V}$. The settling time of the PID, the fuzzy logic, and the switchingbased clustering controller were $5.14 \times 10^{-4} \mathrm{~s}, 5.04 \times 10^{-4} \mathrm{~s}$, and $4.88 \times 10^{-4} \mathrm{~s}$ respectively. The switching-based clustering controller allowed for the fastest settling time as compared to the other approaches.

Table 4: A Summary of the Best Controllers for the Initial Test

\begin{tabular}{|c|c|}
\hline & Controller and Values \\
\hline Rise Time & Switching-based Clustering $1.75 \times 10^{-4} \mathrm{~s}$ (fastest) \\
\hline Fall Time & Switching-based Clustering $3.13 \times 10^{-4} \mathrm{~s}$ (fastest) \\
\hline Overshoot & Switching-based Clustering 2.58V (lowest) \\
\hline Initial Value & Same value for all approaches \\
\hline Peak Value & PID 5.64V (highest) \\
\hline Final Value & Switching-based Clustering 3.01V (closest to 3V) \\
\hline
\end{tabular}

A comparison of the second test with a pulsed reference is shown in Table 5. The fuzzy logic controller had the fastest rise time but also had the highest peak value. The PID controller had the fastest fall time. The switching-based clustering controller had the smallest overshoot value. The settling time for the PID, fuzzy logic and the switching-based clustering controller with the new three pulsed input to the gain of the MOSFET were $2.33 \times 10^{-3} \mathrm{~s}, 2.32 \times 10^{-3} \mathrm{~s}$, and $2.34 \times 10^{-3} \mathrm{~s}$.

Table 5: A Summary of the Best Controllers for the Second Test

\begin{tabular}{|c|c|}
\hline & Controller and Values \\
\hline Rise Time & Fuzzy Controller $9.36 \times 10^{-4} \mathrm{~s}$ (fastest) \\
\hline Fall Time & PID $1.39 \times 10^{-3} \mathrm{~s}$ (fastest) \\
\hline Overshoot & Switching-based Clustering 2.94V (lowest) \\
\hline Initial Value & Same value for all approaches \\
\hline Peak Value & Fuzzy Controller 6.16V (highest) \\
\hline Final Value & Fuzzy Controller 3V (closest to 3V) \\
\hline
\end{tabular}

\section{CONCLUSION}

The smart controller approach presented in this paper was implemented using a new switching-based clustering algorithm. This method of control provided a stable voltage output more efficiently than competing methods. The results showed that the proposed method could improve the performance of the buck converter system by $2.7 \%$ in terms of its settling time and by $0.6 \%$ in terms of the overshoot value as compared to the other control methods for buck converters. Future work could address implementing the controller for higher voltage and multi-level converter systems.

\section{ACKNOWLEDGMENTS}

The authors would like to thank the Office of Research Services (ORS) at Loyola University Chicago.

\section{REFERENCES}

[1] M. K. Swathy, M. S. Jantre, M. Y. Jadhav, M. S. M. Labde and M. P. Kadam, "Design and Hardware Implementation of Closed Loop Buck Converter Using Fuzzy Logic Controller," in , " 2018 Second International Conference on Electronics, Communication and Aerospace Technology, Coimbatore, India, 2018.

[2] K. Bendaoud, S. Krit, M. Kabrane, H. Ouadani, M. Elaskri, K. Karimi, H. Elbousty and L. Elmaimouni, "Fuzzy Logic Controller (FLC): Application to Control DC-DC Buck Converter," in International Conference on Engineering \& MIS (ICEMIS), Monastir, Tunisia, 2017.

[3] "Application Areas of Buck Converters," AllAboutCircuits, [Online]. Available: www.allaboutcircuits.com.

[4] G. Muhurcu, E. Kose, A. Muhurcu and A. Yilmaz, "PI's Parameter Optimization based on IWO for Optimal Controlling of a Buck Converter's Output," in International Artificial Intelligence and Data Processing Symposium (IDAP), Malatya, Turkey , 2017.

[5] M. Qin, J. Xu, G. Zhou and Q. Mu, "Analysis and Comparison of Voltage-Mode and Current-Mode Pulse Train Control Buck Converter," in 4th IEEE Conference on Industrial Electronics and Applications, Xi'an, China, 2009.

[6] N. Shinde, S. Sankad and S. L. Patil, "Design and Study Voltage Characteristics of Buck Converter by Matlab Simulink," in 2nd International Conference on Trends in Electronics and Informatics (ICOEI), Tirunelveli, India, 2018.

[7] M. F. N. Tajuddin and N. A. Rahim, "IEEE Symposium on Industrial Electronics \& Applications," in Small-Signal AC Modeling Technique of Buck Converter with DSP based Proportional-Integral-Derivative (PID) Controller, Kuala Lumpur, Malaysia, 2009.

[8] C. Zhou, Q. Zhang, D. D. Ezechias, Y. Gao, H. Deng and S. Qu, "A General Digital PID Controller based on PWM for Buck Converter," in Proceeding of the 11th World Congress on Intelligent Control and Automation, Shenyang, China, 2014.

[9] S. Lodwal, "Conventional Step-Down DC-DC Converter," Mathworks, 2015. [Online].

[10] R. M. Esteves, T. Hacker and C. Rong, "Competitive K-Means, a New Accurate and Distributed K-Means Algorithm for Large Datasets," in IEEE 5th International Conference on Cloud Computing Technology and Science, Bristol, England, 2013.

[11] V. Andries, L. Goras, A. Buzo and G. Pelz, "Automatic Tuning for a DC-DC Buck Converter with Adaptive Controller," in International Symposium on Signals, Circuits and Systems (ISSCS), Lasi, Romania, 2017.

[12] S. Stephen and T. Devaprakash, "Improved Control Strategy on Buck-Boost Converter Fed DC Motor," in Int. Conf. Recent Advancements in Electrical, Electronics and Control Engineering, Sivakasi India, 2011. 